This item was submitted to Loughborough's Research Repository by the author.

Items in Figshare are protected by copyright, with all rights reserved, unless otherwise indicated.

\title{
Conceptual knowledge of the associativity principle: a review of the literature and an agenda for future research
}

PLEASE CITE THE PUBLISHED VERSION

https://doi.org/10.1016/j.tine.2021.100152

PUBLISHER

Elsevier

VERSION

AM (Accepted Manuscript)

\section{PUBLISHER STATEMENT}

This paper was accepted for publication in the journal Trends in Neuroscience and Education and the definitive published version is available at https://doi.org/10.1016/j.tine.2021.100152.

\section{LICENCE}

CC BY-NC-ND 4.0

\section{REPOSITORY RECORD}

Eaves, Joanne, Camilla Gilmore, and Nina Attridge. 2021. "Conceptual Knowledge of the Associativity Principle: A Review of the Literature and an Agenda for Future Research". Loughborough University. https://hdl.handle.net/2134/14109848.v1. 
Conceptual knowledge of the associativity principle: a review of the literature and an agenda for future research

Joanne Eaves ${ }^{a}$

${ }^{a}$ Mathematics Education Centre, Loughborough University, LE11 3TU

Camilla Gilmore $^{a}$

${ }^{a}$ Mathematics Education Centre, Loughborough University, LE11 3TU

Nina Attridge ${ }^{a}$

${ }^{a}$ Mathematics Education Centre, Loughborough University, LE11 3TU

This manuscript is accepted for publication in Trends in Neuroscience and Education 
Abstract

Individuals use diverse strategies to solve mathematical problems, which can reflect their knowledge of arithmetic principles and predict mathematical expertise. For example, ' $6+38-35^{\prime}$ can be solved via ' $38-35=3$ ' and then ' $3+6=9$ ', which is a shortcut-strategy derived from the associativity principle. The shortcut may be critical for understanding algebra, however approximately $50 \%$ of adults fail to use it. We review the research to consider why the associativity principle is challenging and highlight an important distinction between shortcut identification and execution. We also discuss how domain-specific skills and domain-general skills might play an important role in shortcut identification and execution, and provide an agenda for future research. 


\section{Introduction}

Knowledge of arithmetic principles is widely regarded as important for success with mathematics (National Council Of Teachers Of Mathematics, 2000) and for developing mathematical expertise (McMullen et al., 2016). In the last twenty years, the number of studies investigating individuals' understanding of arithmetic principles has increased (Star, 2005) and as a result, seven arithmetic principles are now widely discussed: identity, negation, complementarity, commutativity, inversion, equivalence and associativity (Kilpatrick et al., 2002). Table 1 describes these principles.

Table 1: Description of seven arithmetic principles that are often discussed in the mathematical cognition literature.

Arithmetic principle Identity

Negation

Complementarity

Commutativity

Inversion

Equivalence

Associativity
Description

If an arithmetic operation produces a given result, then repetition of the same operation will produce the same result.

Subtracting an integer gives the same result as adding its additive inverse, e.g. " $2-3$ " $=$ " $2+(-3)$ ".

If $a+b=c$ then $c-b=a$ and $c-a=b$.

Some operands can be performed in any order, e.g. $a+b=b+a$.

Addition and subtraction, and multiplication and division involving the same value result in no change.

Two sides of an equation are equal and interchangeable.

Some problems can be solved by decomposing and recombining groups of operations.

Studies have found that many individuals have an inadequate understanding of arithmetic principles, because they fail to use strategies that those principles encourage, or fail to understand the basis of the strategy that they choose (Robinson \& LeFevre, 2012). One principle that individuals have particular difficulty with is associativity (Robinson et al., 2017), the property that permits some operations to be performed in a different order from that in which they are presented. Education practitioners have called for individuals' understanding and use of arithmetic principles to improve, including associativity (National Mathematics Advisory Panel, 2008) because it may play an important role in the transition from basic to more advanced mathematics (Barnett \& Ding, 2018). 
However, compared to other arithmetic principles there is much less research into associativity. Studies to date mostly come from cognitive psychology (see Table 2 for a summary of relevant literature) with a handful from the mathematics education literature (Barnett \& Ding, 2018; Ding et al., 2012; Larsen, 2010; Shumway, 1974) and those from cognitive psychology most often used associativity as a comparison for other principles rather than investigating it as a standalone concept. We aim to synthesise this research by first reviewing the history, importance and measurement issues associated with the principle, and summarising the evidence of how frequently individuals apply the principle when solving arithmetic problems. We then make an important distinction between identifying and executing arithmetic strategies, and suggest that the origin of individuals' low use of the associativity shortcut may lie in the skills required for these two processes. In the final section we outline priority questions for the field and suggestions for how they could be investigated. The primary goal for research, we suggest, should be to understand why the principle is rarely applied during problem-solving and this review discusses the possible explanations that future research could explore.

This review draws on research into other principles that have richer research histories than associativity, including a) inversion, the principle that addition and subtraction, and multiplication and division, are opposite operations (Baroody, 2003), b) equivalence, the principle that two sides of an equation are equal and interchangeable (Kieran, 1981) and c) subtraction complementarity, which refers to the insight that if ' $a-b=c$ ' then ' $a-c=b$ ' (Baroody et al., 2009; Canobi, 2005). Research into these principles could serve as a guide for future investigations into associativity.

\section{Definition and history}

The associativity principle (hereafter 'associativity') states that ' $(a+b)+c=a+(b+c)$ '. In other words, because some operations are related, problems can sometimes be solved by first decomposing and then recombining their problem sets (Canobi et al., 1998) and the answer to a problem can be the same regardless of which group of operations is dealt with first (e.g. $a+b-c=b$ 
$-c+a)$. In psychology studies, the principle has been studied in different situations, such as with problems that contain only addition (e.g. $a+b+c=b+c+a$ ), addition and subtraction (e.g. $a+b-c$ $=b-c+a$ ), only multiplication (e.g. $a \times b \times c=b \times c \times a$ ), or multiplication and division (e.g. $a \times b \div c$ $=b \div c \times a)$, (Canobi, 2005; Robinson \& Ninowski, 2003). In mathematics education studies, the principle has most often been studied in the context of addition-only and multiplication-only problems (Barnett \& Ding, 2018).

Research has made good progress in uncovering individuals' knowledge of some principles, for example, numerous studies have focused on inversion and equivalence. However, this has left other principles, such as associativity, underexplored. While inversion has been investigated by psychologists for nearly 70 years (Piaget, 1952), associativity received little attention until the late 1990s. At this time, it was predominantly studied through addition problems $(a+b+c=b+c+a)$ and problems that inferred conceptual knowledge from the strategies used across sequential trials (e.g. recognising the conceptual relationship between ' $3+6+2$ ' and the subsequently presented problem ' $9+2$ '), (Canobi et al., 1998, 2002, 2003). This approach continues to be fruitful for inferring knowledge of associativity (Cragg et al., 2017; Gilmore et al., 2015).

In the decade that followed, the inversion literature (which often used problems of the form ' $a+b-$ $b^{\prime}$ or ' $a \times b \div b^{\prime}$ to infer knowledge of the principle) began to include problems such $a$ ' $^{\prime} a+b-c^{\prime}$ and ' $a \times b \div c$ ' as part of their studies. These problems were labelled as 'standard' or 'control' problems for inversion. The inversion problems were expected to be solved through a shortcut strategy (where the individual avoids the computation ' $b-b^{\prime}$ or ' $b \div b^{\prime}$ and simply picks ' $a$ ') and the control problems were expected to be solved through a left-to-right strategy. Indeed, verbal reports, accuracy and response times confirmed that this was the case (Bryant et al., 1999; Gilmore, 2006; Gilmore \& Bryant, 2006; Robinson et al., 2006). However, in 2000 Klein \& Bisanz noticed that some individuals solved control problems using a 'right-to-left' strategy (e.g. solving ' $6+38-35$ ' by ' $38-$ $35=3^{\prime}$ and then ' $3+6=9^{\prime}$ ), a strategy now known in the psychology literature as an 'associativity 
shortcut' (Eaves et al., 2019, 2020; Robinson et al., 2016; Robinson \& Dubé, 2009a, 2012, 2013). The 'shortcut' strategy is therefore one way of solving ' $a+b-c^{\prime}$ problems; for ' $6+38-35^{\prime}$ it is more efficient than a left-to-right strategy. Although there may be alternative ways in which some people solve ' $a+b-c$ ' problems, left-to-right approaches and right-to-left shortcuts are the main strategies that are discussed in the literature, and that we focus on in this review. After Klein \& Bisanz's (2000) discovery of the shortcut strategy, Robinson \& Ninowski (2003) and Robinson et al., (2006) pushed for ' $a+b-c$ ' problems to be used more widely as a measure of associativity. Their call was acknowledged, and today problems with opposing operations (addition and subtraction or multiplication and division) are a dominant paradigm used to investigate how well individuals understand the principle.

\section{The importance of associativity}

Recently, education practitioners have called for greater research effort to develop students' conceptual knowledge of arithmetic principles and the use of strategies that they permit (National Council Of Teachers Of Mathematics, 2000; Common Core State Standards Initiative, 2012). This is an issue of international relevance given that some countries (UK, USA and Canada) place little emphasis on arithmetic principles in their education curricula, while other countries (Germany, New Zealand) place a strong emphasis on them (Ding et al., 2012). The call is warranted for associativity in particular because it is thought to be one of the principles that helps with students' transition from arithmetic to algebra (Warren, 2003), to help them understand how to use brackets in problems with multiple operations (Gunnarsson et al., 2016), and ultimately to help them progress from elementary to more advanced mathematics.

For example, one way in which understanding associativity may help individuals to progress in mathematics is by encouraging them to interpret algebra problems as 'generalised arithmetic' problems (Alibali et al., 2007; Carraher, 2006; Knuth et al., 2005; Warren, 2003), where using principles on arithmetic problems can help individuals to infer the correct processes for solving 
abstract algebra problems. For example, in the algebraic problem ' $9 x+2=6 x+2 y$ ', an individual could be asked to make a letter the subject of the equation. Along with other principles such as equivalence, associativity could help individuals on this problem because it permits sub-expressions to be solved in a different order from that in which they are presented, and therefore builds an understanding of how to apply transformations to both sides of the equation and re-order groups of operations to obtain the answer.

Finally, associativity may also help individuals to understand when and how to use brackets appropriately in multi-term problems (Gunnarsson et al., 2016). For example, in the problem ' $a-b+$ $c^{\prime}$, a left-to-right strategy ('a - b' first) and a right-to-left strategy ('b $+c^{\prime}$ first) result in different answers and brackets are needed to resolve this ambiguity. However, brackets are not required on some problems, for example ' $\mathrm{a}+\mathrm{b}-\mathrm{c}$ ', where both left-to-right and right-to-left strategies result in the same answer. Using brackets when they are not necessary, as would be the case for the problem ' $a+b-c$ ', has been found to have negative consequences on mathematical understanding such as understanding of the order of operations (Gunnarsson et al., 2016). Knowledge of associativity may therefore reduce the reliance on instructive devices, such as brackets, for solving arithmetic problems.

\section{Measurement}

Measuring knowledge of arithmetic principles sparks animated debate (Crooks \& Alibali, 2014; Rittle-Johnson \& Schneider, 2014), and associativity is no exception. Methods broadly divide into explicit and implicit techniques, and typically involve presenting individuals with arithmetic problems (e.g. ' $a+b-c^{\prime}$ or ' $a \times b \div c^{\prime}$ ) that they are asked to evaluate, justify or compare (explicit measures), or solve themselves (implicit measures). For example, if an individual reports using a right-to-left shortcut strategy on ' $a+b-c^{\prime}$ or ' $a \times b \div c^{\prime}$, the researcher has explicit evidence that they have applied their knowledge of associativity. However, while self-reports provide explicit evidence for the use of a strategy, they also require conscious awareness and verbal skills to describe the strategy 
used, making a reliance on them alone sub-optimal (Crooks \& Alibali, 2014). Implicit techniques, which infer strategy use from solution accuracy and response times, are therefore often used in conjunction with verbal reports (Robinson \& Ninowski, 2003; Robinson et al., 2006, 2017; Robinson \& Dubé, 2009a, 2009b, 2013).

For associativity, one recent development is the suggestion that shortcut use can be measured implicitly by comparing performance on problems that are 'conducive' to the principle to those that are not (Edwards, 2013). Conducive problems (e.g. ' $16+47-45$ ') encourage the use of associativity because the shortcut yields a small positive number $(47-45=2)$, which makes a right-to-left strategy less computationally demanding. Non-conducive problems (e.g. ' $36+27-45^{\prime}$ ) are designed not to be easier to solve using shortcuts and instead encourage a left-to-right strategy. Studies on inversion sometimes used ' $a+b-c$ ' problems as control problems for inversion, which often varied in how conducive they were to an associativity shortcut. Here, we focus on conducive and nonconducive problems as a way to infer knowledge of associativity. For example, the digits in conducive problems can be selected such that the difference in efficiency between a left-to-right strategy and a shortcut strategy is substantial, and therefore incentivises individuals to use the shortcut. If accuracy and response times are better on conducive than non-conducive problems, it can be inferred that an individual is likely to have used the shortcut on the conducive problems.

Three studies have compared performance on conducive and non-conducive associativity problems (Eaves et al., 2019, 2020; Edwards, 2013). Edwards (2013) found that self-reported shortcut use was significantly higher on ' $a \times b \div c^{\prime}$ problems that were conducive to a shortcut than those that were not conducive. Eaves et al., (2019) found that self-reported users of the shortcut solved more conducive $' a+b-c$ ' problems in a restricted timeframe than individuals who did not self-report using the shortcut, but that self-reported users and non-users did not differ on non-conducive ' $a+b$ - $c^{\prime}$ problems. Comparing performance on conducive and non-conducive problems is therefore one way that researchers could investigate implicit associativity shortcut use independently from other 
concepts. It may also be a useful approach for researchers wanting to measure strategy use in an unbiased way. To the best of our knowledge, all but one previous study (Eaves et al., 2020) that used self-reported solution strategies did so by asking participants to describe the strategy they used multiple times in a short timeframe, i.e. after every trial (e.g. see Dubé, 2014 and Robinson \& Dubé, 2009a, 2009b with children and adolescents). For adults, this approach may be problematic because repeatedly asking them about strategy use could provide a hint that alternative strategies exist and influence how a person solves subsequent problems (Haider et al., 2014; Siegler \& Stern, 1998). By comparing accuracy and reaction time on conducive and non-conducive problems, use of the associativity shortcut can be inferred without inadvertently encouraging it through repeated questioning.

We note that the inferences that can be drawn from both explicit and implicit measures, however, are not clear-cut because strategies and knowledge of arithmetic principles are not perfectly related (Baroody \& Gannon, 1984; Baroody, 1999; Crooks \& Alibali, 2014; Schneider \& Stern, 2010). Using a shortcut does not guarantee a 'deep' understanding of the principle (Baroody et al., 2007; Star, 2005), i.e. an understanding that because some operations are related (e.g. addition and subtraction), groups of operations can sometimes be solved in different orders. Instead, shortcut use could reflect 'superficial' understanding, where individuals follow a right-to-left approach due to previous experience or memorised procedures (Baroody, 1999; Baroody \& Gannon, 1984; KarmiloffSmith, 1992; Robinson \& Dubé, 2012; Siegler \& Stern, 1998). The reverse case is also plausible, where individuals have a deep understanding of associativity but fail to select a shortcut (see sections 6 and 7). Scholars investigating the understanding of any arithmetic principle through strategy use should therefore remember that the strategy an individual uses does not just reflect how well an individual understands a principle, but also their the ability and willingness to apply their knowledge (Siegler, 1988). 
Furthermore, knowledge of a principle is not "all-or-none" (Gilmore, 2006, p7); as individuals may understand some part(s) or form(s) of a principle, but not others (Bryant et al., 1999; Crooks \& Alibali, 2014) or be able to apply the principle in some situations but not others. Shortcut use on arithmetic problems is just one way of measuring knowledge of a principle and the failure to use a strategy does not imply a lack of understanding of all forms of a principle. Some researchers have therefore used multiple tasks to measure individuals' understanding, such as tasks where problems are presented with objects, tasks where they explain why a strategy is valid, and tasks where they evaluate and choose between different strategies (see Crooks \& Alibali, 2014 for an overview). Bisanz et al., (2009) put forward a framework where these tasks were organised by a) how explicit/implicit they were and $b$ ) the breadth of understanding that could be inferred from them. For example, recognising the validity of a strategy on one task demonstrates implicit, narrow understanding of a principle, while explaining a principle on a variety of related tasks demonstrates explicit, broad understanding. To characterise the breadth and depth of an individual's understanding, they therefore need to complete a variety of related measures.

In the case of associativity, few studies have used multiple tasks to assess individuals' understanding (see Robinson \& Dubé, 2012, for an exception) and more are warranted to capture the extent to which individuals understand and apply their knowledge of the principle. In the cases of inversion, complementarity and equivalence for example, children demonstrate a better understanding when problems are presented in a concrete format with objects and pictures than an abstract format with digits (Canobi, 2005; Canobi \& Bethune, 2008; Gilmore \& Bryant, 2006; Patel \& Canobi, 2010). No studies have quantitatively compared performance on concrete and abstract associativity problems, although Klein \& Bisanz (2000) anecdotally reported that on at least one occasion, $25 \%$ of preschoolers used associativity shortcuts on problems presented with poker chips. Asghari \& Khosroshahi (2016) observed similar behaviours in $5-6$ year olds. Thus, it can be argued that adults are likely to have some form of understanding of associativity given that young children do, and that 
difficulties may arise when applying that knowledge to more abstract ' $a+b-c^{\prime}$ or ' $a \times b \div c^{\prime}$ digitbased problems.

\section{Low use of the associativity shortcut}

Compared to simpler concepts such as inversion, children dislike associativity, and prefer to operate left-to-right rather than use a shortcut (Robinson \& Dubé, 2012; Robinson et al., 2016). For example, on the problem ' $6+38-35^{\prime}$, they prefer to perform the addition first (' $6+38=44$ ') and then the subtraction ('44-35=9'), rather than use a right-to-left shortcut ('38-35=3' and then ' $3+6=9^{\prime}$ ). At the age of $6-10$ years, inversion shortcuts are used approximately $35-60 \%$ of the time (Robinson \& Dubé, 2012, 2013), a rate that matches adults by the age of 14 years (approximately 70 - $75 \%$ on multiplication-division inversion problems and $90-95 \%$ on addition-subtraction inversion problems) (Dubé \& Robinson, 2010a; Dubé, 2014; Robinson \& Ninowski, 2003). In comparison, the use of associativity shortcuts lags behind (see Table 2 for a summary of relevant literature). Children aged 7 - 10 years use associativity shortcuts only $10-25 \%$ of the time (Robinson \& Dubé, 2009a), a rate that remains low (approximately 30\%) in early adolescence, aged 11 - 14 years (Robinson et al., 2006). Even in adulthood (aged 18 years and over), there is substantial room for improvement, where associativity shortcut use hovers around $50-60 \%$ on addition-subtraction problems (Robinson \& Ninowski, 2003; Robinson \& Beatch, 2016) and even some qualified teachers have a poor understanding of the principle (Barnett \& Ding, 2018).

These statistics are also interesting to compare to equivalence, because equivalence has a reputation for being the most poorly understood arithmetic principle by school-aged children (Kieran, 1981). Many children struggle to define the equals sign and make consistent errors on problems of the format ' $a+b=c+$ ?' where they overlook 'c' (McNeil \& Alibali, 2005). Indeed, a recent study found that children applied the equivalence principle to problems in this format only 10 - 40\% of the time (Robinson et al., 2017). However, in this same study the application of associativity to ' $a+b-c$ ' problems was even lower, at $10-15 \%$. Greater recognition of the 
associativity principle and the fact that few individuals apply it on ' $a+b-c^{\prime}$ problems is therefore warranted.

We note that presentation format can influence the strategy an individual uses on two-term arithmetic problems (Caviola et al., 2018). Similarly, shortcuts on ' $a+b-c$ ' problems may be created in other ways, for example in ' $38+6-35$ ' the location of the shortcut is split across the left and right of the problem ('38-35=3' and then ' $3+6=9$ '). However, we know of no studies that have investigated associativity shortcuts in this 'split' format (i.e. 'a $-c^{\prime}$ ', then ' $+b^{\prime}$ '), and therefore focus on shortcuts located on the right-hand side $(' b-c$ ' then ' $+a$ ') for the purpose of this review. 
Table 2: A summary of relevant studies that have used explicit and implicit measures of average performance on 'a $+b-c^{\prime}$ and 'a $\times b \div c^{\prime}$ problems that are conducive to the associativity shortcut

\begin{tabular}{|c|c|c|c|c|c|}
\hline Study & Age (years) & Operation & $\begin{array}{l}\text { Percent of trials on which the } \\
\text { shortcut was used* }\end{array}$ & Speed $(s)^{*}$ & Accuracy (\% correct)* \\
\hline Robinson \& Ninowski, & & Addition-subtraction & $58 \%$ & 3.5 & $78.5 \%$ \\
\hline & & Multiplication-division & $32.5 \%$ & 7 & $76.5 \%$ \\
\hline Robinson et al., & 11 & Addition-subtraction & $11.5 \%$ & 8 & $85 \%$ \\
\hline$(2006)^{\dagger}$ & & Multiplication-division & $0 \%$ & 18 & $65.5 \%$ \\
\hline & 12 & Addition-subtraction & $23 \%$ & 6 & $87.5 \%$ \\
\hline & & Multiplication-division & $2.5 \%$ & 11.5 & $78 \%$ \\
\hline Robinson \& Dubé, & 7 & & $12 \%$ & 17.5 & $50 \%$ \\
\hline (2009b) & 8 & Addition-subtraction & $26 \%$ & (averaged & (averaged \\
\hline & 9 & & $24 \%$ & across grade) & across grade) \\
\hline $\begin{array}{l}\text { Dubé \& Robinson, } \\
(2010 b)^{\dagger+}\end{array}$ & Adults & Multiplication-division & $44 \%$ & 5 & $98-74 \%$ \\
\hline
\end{tabular}




\begin{tabular}{|c|c|c|c|c|c|}
\hline Robinson \& Dubé, & 7 & & $13 \%$ & 12 (averaged & $65 \%$ (averaged \\
\hline \multirow[t]{3}{*}{$(2012)$} & 8 & & $33 \%$ & across grade) & across grade) \\
\hline & & Addition-subtraction & & & \\
\hline & 9 & & $16 \%$ & & \\
\hline Robinson \& Dubé, & 8 & & $11 \%$ & 5.5 & $21 \%$ \\
\hline \multirow[t]{2}{*}{ (2013) } & 9 & Addition-subtraction & $8.5 \%$ & 6.5 & $37.5 \%$ \\
\hline & 10 & & $24.5 \%$ & 5.5 & $50.5 \%$ \\
\hline Edwards (2013) & Adults & Multiplication-division & $24.5 \%$ & $2-8$ & $93.5 \%$ \\
\hline \multirow[t]{5}{*}{ Dubé (2014) } & 12 & & $14 \%$ & 10 & $72 \%$ \\
\hline & 13 & & $29.5 \%$ & 5.5 & $83.5 \%$ \\
\hline & & Multiplication-division & & & \\
\hline & 14 & & $39.5 \%$ & 5.5 & $89 \%$ \\
\hline & Adults & & $54 \%$ & 4.5 & $91.5 \%$ \\
\hline Robinson \& Beatch, & Adults & Addition-subtraction & $65 \%$ & 2.5 & $85 \%$ \\
\hline$(2016)^{\dagger}$ & & Multiplication-division & $75 \%$ & 2.5 & $75 \%$ \\
\hline \multirow[t]{3}{*}{ Robinson et al., (2016) } & 6 & & $0 \%$ & 2.5 (averaged across & 42.5\% (averaged \\
\hline & 7 & Multiplication-division & $7.5 \%$ & grade) & across grade) \\
\hline & 8 & & $14.5 \%$ & & \\
\hline
\end{tabular}




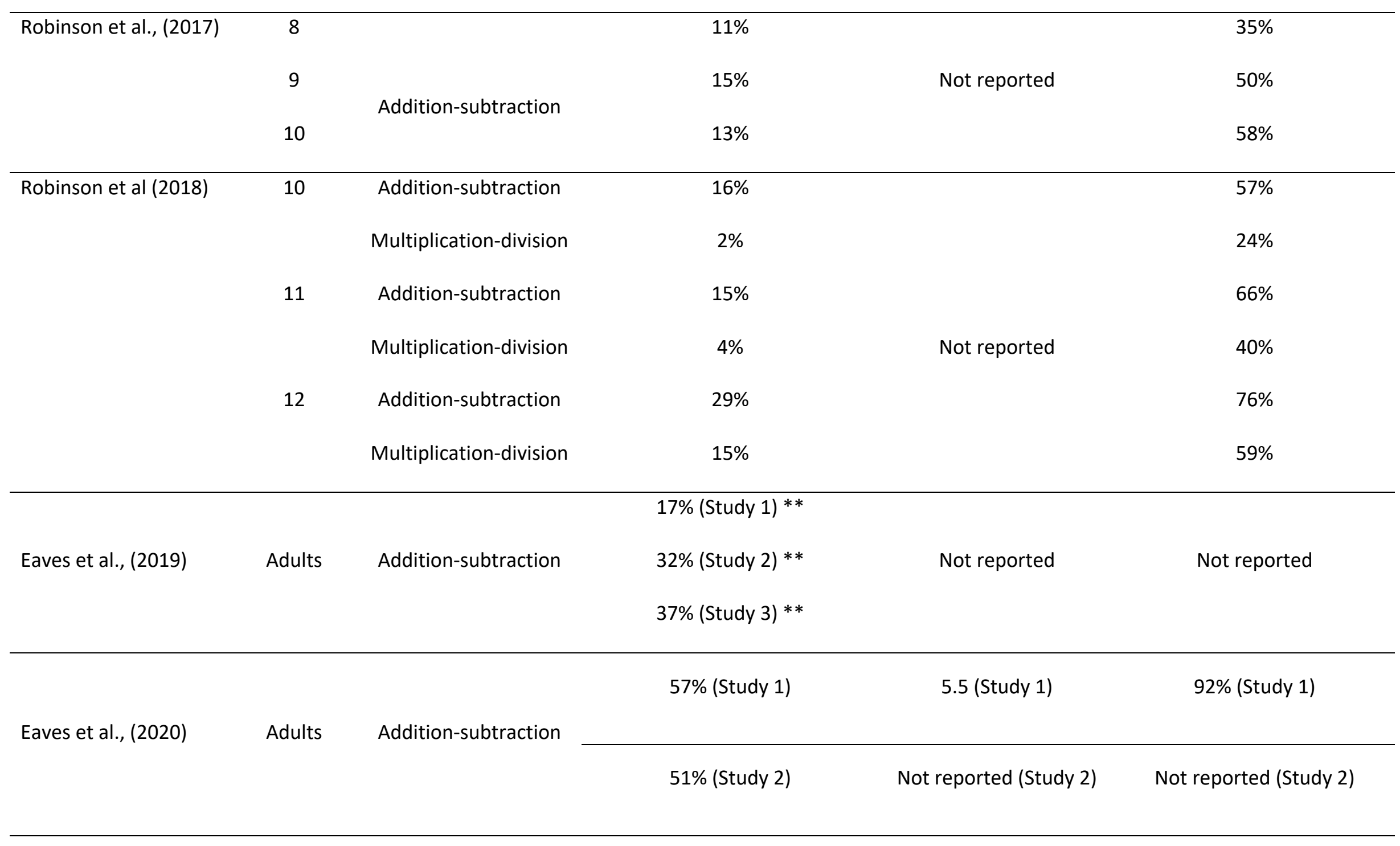


† Statistics were reported for conducive and non-conducive problems combined rather than separately.

†+ Some statistics were reported for different clusters of individuals, rather than the whole sample.

* Percent, speed and accuracy are approximate scores that are averaged over small and large problems. Self-reports are used to determine percent scores.

** The percent of individuals who self-reported using the shortcut to the first associativity problem presented. 
Studies have also uncovered different groups or clusters of individuals based on how they solve ' $a+$ $b-c$ ' associativity problems and ' $a+b-b$ ' inversion problems. These groups are often referred to as 'dual concept', 'inversion only', 'negation' and 'no concept' (Dubé \& Robinson, 2010a, 2010b; Dubé, 2014; Robinson \& Dubé, 2009b, 2013, 2017; Robinson et al., 2018), and represent individuals with different levels of understanding. Those in the dual concept cluster use shortcuts frequently on both inversion and associativity problems, those in the inversion cluster use them on only inversion problems, and those in the 'no concept' cluster use neither. 'Negation' is a term used in the literature to describe how some individuals solve ' $a+b-b$ ' inversion problems, where an individual initially uses a left-to-right strategy but then switches to a shortcut part-way through calculating, potentially after realising that the last two digits are the same. One notable finding is that these clusters exist in all age groups, children and adults alike (Dubé, 2014; Dubé \& Robinson, 2010a; Robinson \& Dubé, 2009b) and that there is no cluster of individuals who understand associativity but not inversion. Individual differences in selecting shortcut strategies therefore exist at all stages of development and understanding inversion may be an important precursor to understanding associativity. Research studies need to investigate why these difficulties and individual differences arise if they are to improve knowledge of arithmetic principles (National Council Of Teachers Of Mathematics, 2000). We address this topic in section 7.

\section{Identifying vs executing shortcut strategies}

Arithmetic strategies are often discussed in terms of four lower-level components and two higherlevel components (Lemaire \& Siegler, 1995; Verschaffel et al., 2009). Lower-level components include repertoire (the number of strategies an individual knows), selection (the strategy an individual chooses from their repertoire to solve a problem), frequency (the number of times an individual uses a strategy) and efficiency (the accuracy and speed with which a strategy is performed). Higher-level components consist of flexibility and adaptivity, which refer to the ability to switch between strategies, and in a way that maximises efficiency, respectively. In this review, strategy selection on ' $a+b-c^{\prime}$ problems (left-to-right or a shortcut) is the primary interest. More 
specifically, this review focuses on what may be deemed a subcomponent of strategy selection, a process that we call identification.

Identifying an arithmetic strategy is distinct from executing it. Identification refers to noticing a strategy for the first time on a given task or within a particular context. In other words, it is the timepoint when an individual first recognises the validity of a strategy for solving a set of problems, akin to what Shrager \& Siegler (1998) call 'strategy discovery'. Where the strategy is efficient (and more efficient than alternative strategies) identification is likely to be synonymous with the first-time use of it. Identification is distinct from executing a strategy, which refers to all of the processes involved in performing the strategy after it has been identified, i.e. the decision to use it and the process of calculating it. Execution differs from efficiency, where efficiency refers to the speed and accuracy with which the calculations (execution) have been performed. This distinction between identification and execution can be made apparent by comparing ' $a+b-b$ ' inversion problems to conducive ' $a+b$ - $c^{\prime}$ associativity problems. To use a shortcut on ' $a+b-b$ ' inversion problems, identification and execution coincide, in the sense that if an individual has identified the inversion shortcut, they have also executed it. However, for ' $a+b-c$ ' associativity problems, an individual may identify the ' $b-c$ ' shortcut but choose not to execute it. Strategy execution has been well researched and is typically measured by averaging solution accuracy and response time to multiple problems that are solved using the same strategy. Measuring the point of identification is more difficult because it requires microgenetic techniques, techniques where performance is measured and compared at multiple points in a narrow timeframe. For example, in our earlier work (Eaves et al., 2020) we developed a novel, implicit method for measuring identification; we recorded participants' solution times to conducive ' $a+b-c$ ' problems and compared them on a trial-by-trial basis to determine when participants' became more efficient in solving them. We referred to this as the 'identification point'. Studies investigating individuals' knowledge and application of arithmetic principles rarely mention the distinction between identification and execution. However, we judge that the distinction is important for scholars investigating individuals' understanding of arithmetic principles because it 
highlights that the reason why an individual may find a strategy difficult may be due to one process more than the other.

One consequence of making this distinction is that the two processes of strategy identification and execution might draw on different sets of underlying cognitive skills (e.g. attention, working memory), or different levels of those skills. Individuals with different profiles of cognitive skills may therefore find either strategy identification or strategy execution more difficult. Improving the application of arithmetic principles (National Mathematics Advisory Panel, 2008) might therefore require an individualised approach, where individuals' levels of different skills are considered. For example, an individual might have a good understanding of the principle and the ability to compute the calculations involved in the shortcut (' $b-c^{\prime}$ and then ' $+a$ ') but fail to identify it due to difficulties, for example, with attention or inhibition (see Section 7). Alternatively, an individual may notice the relevance of ' $b-c$ ' and identify the shortcut but not execute it if they are sufficiently efficient in calculating left-to-right. In the following section we consider the skills that might be required in the processes of identification and execution in more detail.

We emphasise that this distinction is relevant to researchers investigating a variety of arithmetic principles, not just associativity. For example, the distinction can be applied to commutativity, which is sometimes measured through the 'tens strategy' where ' $4+37+6$ ' is solved by ' $4+6=10^{\prime}$ and then ' $10+37=47$ ', or through a 'look back' strategy where solving ' $7+6$ ' helps to subsequently solve ' $6+7$ ' (Godau, 2014). The calculations in both strategies should be straightforward for adults to execute, but they may be difficult to notice or identify. Equally, individuals may identify the strategy but fail to execute it if they incorrectly believe that looking back to a previous problem is not permitted (Peters et al., 2010; Robinson \& LeFevre, 2012).

\section{Skills involved in identifying and executing shortcut-strategies}

We theorise that a variety of skills could be required to notice and select a strategy for the first time (strategy identification), as well as to perform the computations involved in applying the strategy 
(strategy execution). These skills may be domain-specific or domain-general (see Figure 1). Domainspecific skills apply to the context of interest (in this case, mathematics) while domain-general skills apply to a broad range of tasks. We suggest that varying levels of domain-specific and domaingeneral skills might be involved in each process.

\section{INSERT FIGURE 1 HERE}

Figure 1: Skills that might be required to identify and execute the associativity shortcut on conducive $' a+b-c$ ' problems. Thicker lines are hypothesised to play a greater role in each process. Solid lines indicate a hypothesised positive relationship, dashed lines indicate a hypothesised negative relationship.

Calculation skill and knowledge of the order of operations are two domain-specific skills that might be important for both identifying and executing the associativity shortcut. First, proficient calculation skills (accurate and quick calculations) could help individuals to identify the shortcut as it may give them time to solve a conducive problem through multiple strategies (e.g. left-to-right and a shortcut), compare the result of those strategies, and deduce that the shortcut is valid if both strategies return the same answer. However, proficient calculation skills might reduce the likelihood of executing the shortcut if the individual calculates a left-to-right strategy with similar accuracy and speed as the shortcut itself. These two possibilities could be investigated in future research.

Knowledge of the order of operations may also be important for both processes. The associativity literature rarely discusses the order of operations, but it is a factor that could be very relevant. It refers to the convention (Zakis \& Rouleau, 2017) that for problems with mixed operations (e.g. '2 + 4 $\times 5^{\prime}$ ), multiplication and division should be performed before addition and subtraction, but within multiplication and division and within addition and subtraction order does not alter the result. In the mathematics education literature, case studies, interviews and analyses of the errors individuals make when solving multi-term problems suggest that some individuals have misconceptions with 
the acronyms that are used to teach it (Hewitt, 1999). For example, in the United States, the acronym 'PEMDAS' ('Parentheses, Exponents, Multiplication, Division, Addition, Subtraction') is used. Some individuals have a literal interpretation of this acronym and incorrectly believe that multiplication must be performed before division, and addition must be performed before subtraction (Glidden, 2008). In our research some individuals report having a 'left-to-right' interpretation, and incorrectly believe that if only multiplication and division are present in the problem, or only addition and subtraction, then the problem must be solved in a left-to-right manner (Eaves, Attridge, \& Gilmore, in prep). Literal and left-to-right interpretations could hinder the search for the shortcut on conducive ' $a+b-c$ ' problems because a) the addition is earlier in the acronym and b) the addition is presented on the left-hand side of the problem, respectively. Similarly, for an individual who does notice and identify ' $b-c$ ', they may refrain from executing it if they have a strong literal or left-to-right misconception. This may be similar to, or even explain why, some children say that they see shortcuts as "cheating" (Robinson \& Dubé, 2012).

Domain-general skills include attention, working memory, inhibition and switching, all of which are frequently suggested to be important for mental arithmetic. There are several reviews and metaanalyses of their role in executing calculations (DeStefano \& LeFevre, 2004; Friso-Van Den Bos et al., 2013; Peng et al., 2016; Raghubar et al., 2010; Yeniad et al., 2013) and scholars have begun to hypothesise that they may be specifically important for solving three-term inversion and associativity problems (Robinson et al., 2018; Robinson \& Dubé, 2012). In what follows we focus on identification, and discuss mechanisms for how domain-general skills might help individuals to identify arithmetic strategies rather than execute them. The roles of the skills are not necessarily mutually exclusive and may operate together.

First, attention is a domain-general skill that consists of different components (see Petersen \& Posner, 2012 and Robertson et al., 1996 for more in-depth discussion); selective attention refers to the prioritised processing of certain stimuli (Zentall, 2005) and spatial attention refers to the 
prioritised processing of information at a relevant location (Kim \& Cave, 1995). In the context of identifying the shortcut in conducive ' $a+b-c$ ' associativity problems, these components are likely to play a similar role of helping to direct visual resource toward the location of ' $b-c$ ' on the righthand side. Indeed, in one model of strategy discovery, the Strategy Choice and Discovery Simulation model (SCADS*), attention is the first cognitive process hypothesised to be required for identifying the $' b-b$ ' shortcut on ' $a+b-b$ ' inversion problems (Siegler \& Araya, 2005).

Second, working memory may help individuals to identify the associativity shortcut by enabling them to build 'mental models' of novel problems (Edwards, 2013; Laski et al., 2013). Mental models refer to visual images of problems that are spatially represented in memory. Being able to hold a mental image of ' $a+b-c$ ' problems in mind might allow individuals to move their attention around the problem, and from one group of operations ('a $\left.+b^{\prime}\right)$ to another ('b $\left.-c^{\prime}\right)$ in order to locate the shortcut. After locating the shortcut individuals might then need working memory to evaluate the subexpression ' $b-c$ ' (i.e. to judge whether it is easy or difficult), navigate back to the left-hand side, compare it to ' $a+b$ ', and select the strategy that they prefer. For a more in-depth discussion of the structure and role of working memory in arithmetic, please see Baddeley \& Hitch, (1974), Cowan, (2016), Cragg et al (2017), Edwards (2013) and Rasmussen et al (2003).

Inhibition refers to the ability to stop or override a mental process with or without instruction (Macleod, 2007). It may enable identification by helping individuals to resist interference from irrelevant information (e.g. the digit ' $a$ ' in the context of ' $a+b-c$ ' problems), help them to forget previously learnt material (e.g. rules or procedures they were taught at school), and help them to resist using pre-potent strategies (i.e. strategies that have become familiar through practice). In western societies, one would expect the pre-potent strategy on ' $a+b-c^{\prime}$ problems to be a left-toright approach because classroom-based mathematics teaches and encourages individuals to solve problems in a left-to-right manner (Torbeyns et al., 2009). In order to identify the associativity shortcut, these strategies must therefore be suppressed and counteracted. For a more in-depth 
discussion of the structure and role of inhibition in arithmetic, please see Cyders \& Coskunpinar, (2011), Dempster (1993), Dubé \& Robinson (2010b), Friedman \& Miyake (2004), Gilmore et al., (2015), Harnishfeger \& Pope (1996), Hasher et al., (2007) and Nigg, (2000).

Lastly, switching refers to changing from one mental set to another (Yeniad et al., 2013). Switching might help individuals to identify the shortcut by allowing them to change from a (non-shortcut) strategy that they executed on a previous problem, to considering alternative strategies on the current problem. For example, in everyday settings and experimental studies, individuals are presented with a variety of arithmetic problems that can be solved through different strategies. To identify the shortcut, they therefore need to be able to change from one mindset or previously used approach, to another. This might involve shifting the focus of their attention, i.e. from the left to the right, or from one type of operation (addition first) to another (subtraction first). Research into switching skills in mathematics are still at a very early stage, however relevant papers for a more indepth discussion include Andersson (2008), Cragg et al., (2017), Gilmore et al., (2018), Watchorn et al., (2014) and Yeniad et al. (2013).

Most of the research that has investigated the role of domain-general skills in the understanding and application of arithmetic principles focuses on children, with problems that measure the application of simpler principles such as inversion, commutativity and complementarity (e.g. Cragg et al., 2017; Dubé \& Robinson, 2010; Fyfe et al., 2017; Gilmore et al., 2015; Gilmore et al., 2018; Rasmussen et al., 2003). A handful of studies have included three-term associativity problems: collectively they provide some evidence that in children, inhibition might be related to the use of additionsubtraction inversion and associativity shortcuts (Robinson \& Dubé, 2013) and that in adults, spatial skills may be important (Edwards, 2013). No studies have explored working memory and switching with associativity problems, although findings from the inversion literature indicate that they may play a role (Dubé \& Robinson, 2010). Attention is theoretically expected to play a role in solving inversion problems (Siegler \& Araya, 2005) but there is no empirical evidence that it is important on 
' $a+b-c$ ' and ' $a \times b \div c^{\prime}$ problems (Dubé \& Robinson, 2010b; Eaves et al., 2020). Further research into the role of domain-specific and domain-general skills in strategy identification and execution is therefore warranted.

\section{Future research}

Only three published studies have investigated associativity as a standalone concept, rather than as a comparison for other principles (Eaves et al., 2019, 2020; Edwards, 2013). Given the theoretical importance of associativity in algebra learning and the transition from basic to advanced mathematics, further research is warranted. Indeed, associativity may be as important as equivalence to progressing in mathematics, and of similar or even greater difficulty for individuals to understand and apply (Robinson et al., 2017). Associativity should therefore be investigated with as much rigour, and the equivalence literature could serve as a guide for how. Substantial research effort has been invested into equivalence, with studies investigating attention and perception, working memory, teaching materials, prior conceptions, its relation to subsequent algebra learning, and how it can be taught (Alibali et al., 2017; Chesney et al., 2018; Crooks \& Alibali, 2013; Fyfe et al., 2017; Knuth et al., 2006; McNeil et al., 2006, 2011, 2012). Associativity research could benefit by using that literature as a guide for the range of questions that are important to consider, and for generating ideas of methodologies that could be used to answer them, which we now discuss.

We propose a series of priority research questions for the field. The first question we need to address is "why are associativity shortcut strategies used so infrequently?" In this review we highlighted a selection of domain-specific and domain-general skills that might be important for identifying and executing the shortcut. Correlational and experimental studies in children, adolescents and adults could be conducted to investigate whether and to what extent their role is empirically supported. The studies in section 7 offer a starting point for how they could be investigated. To understand how those skills help an individual select the shortcut strategy though, new methods might need to be created. For example, measures that can separate the process of 
strategy identification from strategy execution (Eaves et al., 2020) might be more likely to capture the contribution of the skills involved because they target mechanisms more precisely (i.e. identification or execution).

The second question that we need to answer is whether knowledge of arithmetic procedures (i.e. the order of operations) and knowledge of the associativity principle conflict. We identified misconceptions of the order of operations as one reason why individuals might not execute the associativity shortcut. This offers a different perspective on the relationship between procedural and conceptual knowledge; most researchers converge on the view that they are positively and iteratively related (Rittle-Johnson et al., 2001), but our suggestion implies that this may not always be the case. In some situations, the two types of knowledge may conflict. This could be tested by mirroring the methodologies that have been used in the equivalence literature; for example, Crooks \& Alibali (2013) intentionally activated misconceptions of the equals sign in adults by exposing them to words such as 'total' and 'sum', and then measured the accuracy with which they reconstructed equivalence problems. For associativity, exposing adults to multi-term problems that contain brackets might activate misconceptions of acronyms such as PEMDAS. This might reduce the identification and execution of associativity shortcuts on subsequent problems, compared to a group without that activation.

The third question relates to our assumption that most adults have some level of understanding of associativity and that difficulties with the principle arise when applying that understanding to the context of digit-based problems. This suggestion could be tested by comparing individuals' strategies on conducive ' $a+b-c^{\prime}$ and ' $a \times b \div c^{\prime}$ associativity problems presented in different formats (e.g. digit, word problems and object-based formats), as has been done with inversion (Gilmore \& Bryant, 2006), equivalence (Sherman \& Bisanz, 2009), commutativity, complementarity (Ching \& Nunes, 2017) and addition-only associativity (Canobi \& Bethune, 2008). If individuals execute associativity 
strategies on ' $a+b-c$ ' and ' $a \times b \div c$ ' more frequently with concrete materials (word problems, objects) than abstract materials (digits), this would lend support to our suggestion.

The fourth question relates to the assumption that associativity serves an important function in higher-level mathematics and algebra (Alibali et al., 2007; Carraher, 2006; Knuth et al., 2005; Warren, 2003). Although it is a logical suggestion, no studies have empirically investigated whether such a link exists. Again, to mirror the equivalence literature (Knuth et al., 2006) this could be explored by comparing algebra performance in a group of individuals with a good understanding of associativity to a group with a poorer understanding, after controlling for general mathematical achievement.

Perhaps the most challenging research priority is to devise ways that associativity can be optimally taught. This goal is challenging because the principle needs to be taught in a manner that is direct enough for individuals to a) understand the meaning of it, b) correct any misconceptions they may have and c) avoid any confusion with similar principles such as commutativity. This final point is relevant because people have been found to conflate ordering operands (commutativity) with ordering operations (associativity), which is thought to create difficulty when transitioning from arithmetic to algebra (Barnett \& Ding, 2018). Additionally, the principle needs to be taught in a way that does not prescribe solution strategies and instead allows the individual to explore how it can be used in different contexts. The danger with directly teaching strategies is that it can cause some individuals to adopt 'fixed' mindsets, where they persevere with a taught strategy even when it is no longer relevant (ErEl \& Meiran, 2011). This phenomenon is known as the Einstellung effect (Luchins, 1942) and in the case of associativity it could manifest as people applying the same strategy on problems where it is not valid (e.g. solving ' $38-5+6^{\prime}$ by $` 5+6=11^{\prime}$ and then ' $38-11=27^{\prime}$ ). Interventions that teach arithmetic principles must therefore be designed to encourage the use of strategies only when they are appropriate and efficient, and to switch to an alternative when they are not. Techniques that do not prescribe strategies and instead increase awareness of those 
available may be more likely to achieve this (Alfieri et al., 2011; Fuson et al., 1997; Hiebert et al., 1996; Jonsson et al., 2016; Piaget, 1973).

\section{Summary}

Associativity is a principle that many children, adolescents, adults and teachers struggle to apply on arithmetic problems such $a s^{\prime} a+b-c$ ' and ' $a \times b \div c$ '. To date, few researchers have investigated associativity independently of other concepts, with only a handful of studies from the psychology and mathematics education literature. However, the principle is thought to be important for the transition from elementary to more advanced mathematics, and studies that answer calls for further research into it are overdue (National Mathematics Advisory Panel, 2008). We provide a number of priority research questions for the field along with suggestions for how they could be investigated. Furthermore, we suggest that researchers may have overlooked an important distinction between strategy identification and strategy execution, and that we need to consider this distinction when investigating why individuals may not use efficient or adaptive strategies. The distinction may help us to understand whether and how different domain-specific skills (calculation skill and knowledge of the order of operations) and domain-general skills (attention, working memory, inhibition and switching) are involved in applying conceptual knowledge to solve arithmetic problems. Ultimately, we suggest that associativity research could benefit from the lessons learnt in the equivalence literature, which is an equally important and similarly difficult principle with a much richer research history. 


\section{References}

Alibali, M. W., Crooks, N. M., \& McNeil, N. M. (2017). Perceptual suppot promotes strategy generation: Evidence from equation solving. Developmental Psychology, 36, 153-168.

Alibali, M. W., Knuth, E. J., Hattikudur, S., McNeil, N. M., \& Stephens, A. C. (2007). A longitudinal examination of middle school students' understanding of the equal sign and equivalent equations. Mathematical Thinking and Learning, 9, 221-247.

https://doi.org/10.1080/10986060701360902

Andersson, U. (2008). Working memory as a predictor of written arithmetical skills in children: the importance of central executive functions. The British Journal of Educational Psychology, 78(Pt 2), 181-203. https://doi.org/10.1348/000709907X209854

Asghari, A., \& Khosroshahi, L. (2016). Making associativity operational. International Journal of Science and Mathematics Education, 15, 1559-1577.

Baddeley, A. D., \& Hitch, G. (1974). Working Memory. In G. Bower (Ed.), Psychology of Learning and Motivation (Vol. 8, Issue 5044, pp. 47-89). Academic Press.

Barnett, E., \& Ding, M. (2018). Teaching of the associative property: A natural classroom investigation. Investigations in Mathematics Learning, 1, 1-20. https://doi.org/https://doi.org/10.1080/19477503.2018.1425592

Baroody, A. J. (1999). Children's relational knowledge of addition and subtraction. Cognition and Instruction, 17, 137-175. https://doi.org/10.1207/S1532690XCl170201

Baroody, A. J. (2003). The development of adaptive expertise and flexibility: The integration of conceptual and procedural knowledge. In The Development of Arithmetic Concepts and Skills: Constructive Adaptive Expertise. Routledge. https://doi.org/10.4324/9781410607218

Baroody, A. J., Feil, Y., \& Johnson, A. R. (2007). An alternative reconceptualization of procedural and conceptual knowledge. Journal for Research in Mathematics Education, 38, 115-131. 
http://www.jstor.org/stable/30034952

Baroody, A. J., \& Gannon, K. E. (1984). The development of the commutativity principle and economical addition strategies. Cognition and Instruction, 1, 321-339. https://doi.org/10.1207/s1532690xci0103_3

Baroody, A. J., Torbeyns, J., \& Verschaffel, L. (2009). Young children's understanding and application of subtraction-related principles. Mathematical Thinking and Learning, 11, 1-9. https://doi.org/https://doi.org/10.1080/10986060802583873

Bisanz, J., Watchorn, R. P. D., Piatt, C., \& Sherman, J. (2009). On “understanding" children's developing use of inversion. Mathematical Thinking and Learning, 11, 10-24. https://doi.org/10.1080/10986060802583907

Booth, J. L., \& Koedinger, K. R. (2008). Key misconceptions in algebraic problem solving. In B. Love, K. McRae, \& V. Sloutsky (Eds.), Proceedings of the 30th Annual Conference of the Cognitive Science Society (pp. 571-576). Cognitive Science Society.

Bryant, P., Christie, C., \& Rendu, A. (1999). Children's understanding of the relation between addition and subtraction: inversion, identity, and decomposition. Journal of Experimental Child Psychology, 74, 194-212. https://doi.org/10.1006/jecp.1999.2517

Canobi, K. H. (2005). Children's profiles of addition and subtraction understanding. Journal of Experimental Child Psychology, 92, 220-246. https://doi.org/10.1016/j.jecp.2005.06.001

Canobi, K. H., \& Bethune, N. E. (2008). Number words in young children's conceptual and procedural knowledge of addition, subtraction and inversion. Cognition, 108, 675-686. https://doi.org/10.1016/j.cognition.2008.05.011

Canobi, K. H., Reeve, R. A., \& Pattison, P. E. (1998). The role of conceptual understanding in children's addition problem solving. Developmental Psychology, 34, 882-891. https://doi.org/10.1037/0012-1649.34.5.882 
Canobi, K. H., Reeve, R. A., \& Pattison, P. E. (2002). Young children's understanding of addition concepts. Educational Psychology, 22, 513-532.

https://doi.org/10.1080/0144341022000023608

Canobi, K. H., Reeve, R. A., \& Pattison, P. E. (2003). Patterns of knowledge in children's addition. Developmental Psychology, 39, 521-534. https://doi.org/10.1037/0012-1649.39.3.521

Carraher, D. W. (2006). Arithmetic and algebra in early mathematics education. Journal for Research in Mathematics Education, 37, 87-115.

Caviola, S., Mammarella, I. C., Pastore, M., \& LeFevre, J. A. (2018). Children's strategy choices on complex subtraction problems: Individual differences and developmental changes. Frontiers in Psychology. https://doi.org/10.3389/fpsyg.2018.01209

Ching, B. H. H., \& Nunes, T. (2017). Children's understanding of the commutativity and complement principles: A latent profile analysis. Learning and Instruction, 47, 65-79. https://doi.org/10.1016/j.learninstruc.2016.10.008

Common Core State Standards Initiative. (2012). Common Core State Standards for Mathematics. In Common Core State Standards Initiative. http://www.corestandards.org/assets/CCSSI_Math Standards.pdf

Cragg, L., Keeble, S., Richardson, S., Roome, H. E., \& Gilmore, C. K. (2017). Direct and indirect influences of executive functions on mathematics achievement. Cognition, 162, 12-26. https://doi.org/10.1016/j.cognition.2017.01.014

Crooks, N. M., \& Alibali, M. W. (2013). Noticing relevant problem features: Activating prior knowledge affects problem solving by guiding encoding. Frontiers in Psychology, 4, 1-10. https://doi.org/10.3389/fpsyg.2013.00884

Crooks, N. M., \& Alibali, M. W. (2014). Defining and measuring conceptual knowledge in mathematics. Developmental Review, 34, 344-377. https://doi.org/10.1016/j.dr.2014.10.001 
Cyders, M. A., \& Coskunpinar, A. (2011). Measurement of constructs using self-report and behavioral lab tasks: Is there overlap in nomothetic span and construct representation for impulsivity? Clinical Psychology Review, 31, 965-982. https://doi.org/10.1016/j.cpr.2011.06.001

Dempster, F. N. (1993). Resistance to interference: developmental changes in a basic processing mechanism. In M. Howell \& R. Pasnak (Eds.), Emerging themes in cognitive development (pp. 327). Springer.

DeStefano, D., \& LeFevre, J. (2004). The role of working memory in mental arithmetic. European Journal of Cognitive Psychology, 16, 353-386. https://doi.org/10.1080/09541440244000328

Ding, M., Li, X., Capraro, M., \& Capraro, R. (2012). Supporting meaningful initial learning of the associative property: Cross-cultural differences in textbook presentations. International Journal for Studies in Mathematics Education, 5, 114-130.

Dubé, A. K. (2014). Adolescents' understanding of inversion and associativity. Learning and Individual Differences, 36, 49-59. https://doi.org/10.1016/j.lindif.2014.09.002

Dubé, A. K., \& Robinson, K. M. (2010a). Accounting for individual variability in inversion shortcut use. Learning and Individual Differences, 20, 687-693. https://doi.org/10.1016/j.lindif.2010.09.009

Dubé, A. K., \& Robinson, K. M. (2010b). The relationship between adults' conceptual understanding of inversion and associativity. Canadian Journal of Experimental Psychology, 64, 60-66. https://doi.org/10.1037/a0017756

Eaves, J., Attridge, N., \& Gilmore, C. K. (n.d.). The order of operations and the use of associativity strategies.

Eaves, J., Attridge, N., \& Gilmore, C. K. (2019). Increasing the use of conceptually-derived strategies in arithmetic: from inversion to associativity. Learning and Instruction, 61, 1-25. https://doi.org/10.1016/j.learninstruc.2019.01.004 
Eaves, J., Gilmore, C. K., \& Attridge, N. (2020). Investigating the role of attention in the identification of associativity shortcuts using a microgenetic measure of implicit shortcut use. Quarterly Journal of Experimental Psychology, 73, 1017-1035.

Edwards, W. (2013). Underlying components and conceptual knowledge in arithmetic [University of Regina, Saskatchewan]. https://ourspace.uregina.ca/bitstream/handle/10294/5434/Edwards_William_200275843_MA _EAP_Spring2014.pdf?sequence=1

ErEl, H., \& Meiran, N. (2011). Mindset changes lead to drastic impairments in rule finding. Cognition, 119, 149-165. https://doi.org/10.1016/j.cognition.2011.01.002

Friedman, N. P., \& Miyake, A. (2004). The relations among inhibition and interference control functions: A latent-variable analysis. Journal of Experimental Psychology: General, 133, 101135. https://doi.org/10.1037/0096-3445.133.1.101

Friso-Van Den Bos, I., Van Der Ven, S. H. G., Kroesbergen, E. H., \& Van Luit, J. E. H. (2013). Working memory and mathematics in primary school children: A meta-analysis. In Educational Research Review (Vol. 10, pp. 29-44). https://doi.org/10.1016/j.edurev.2013.05.003

Fyfe, E. R., Evans, J. L., Matz, L. E., Hunt, K. M., \& Alibali, M. W. (2017). Relations between patterning skill and differing aspects of early mathematics knowledge. Cognitive Development, 44, 1-11. https://doi.org/10.1016/j.cogdev.2017.07.003

Gilmore, C. K. (2006). Investigating children's understanding of inversion using the missing number paradigm. Cognitive Development, 21, 301-316. https://doi.org/10.1016/j.cogdev.2006.03.007

Gilmore, C. K., \& Bryant, P. (2006). Individual differences in children's understanding of inversion and arithmetical skill. The British Journal of Educational Psychology, 76, 309-331. https://doi.org/10.1348/000709905X39125

Gilmore, C. K., Clayton, S., Cragg, L., McKeaveney, C., Simms, V., \& Johnson, S. (2018). Understanding 
arithmetic concepts: The role of domain-specific and domain-general skills. PLOS ONE, 13, 1-20. https://doi.org/10.1371/journal.pone.0201724

Gilmore, C. K., Keeble, S., Richardson, S., \& Cragg, L. (2015). The role of cognitive inhibition in different components of arithmetic. ZDM, 47, 1-12. https://doi.org/10.1007/s11858-014-0659y

Gilmore, C. K., Keeble, S., Richardson, S., \& Cragg, L. (2017). The interaction of procedural skill, conceptual understanding and executive functions in early mathematics achievement. Journal of Numerical Cognition, 3, 1-23. https://doi.org/https://doi.org/10.5964/jnc.v3i2.51

Glidden, P. L. (2008). Prospective elementary teachers' understanding of order of operations. School Science and Mathematics, 108, 130-136. https://doi.org/10.1111/j.1949-8594.2008.tb17819.x

Godau, C. (2014). Spontaneously spotting and applying shortcuts in arithmetic - a primary school perspective on expertise. Frontiers in Psychology, 5, 1-11.

https://doi.org/10.3389/fpsyg.2014.00556

Gunnarsson, R., Sönnerhed, W. W., \& Hernell, B. (2016). Does it help to use mathematically superfluous brackets when teaching the rules for the order of operations? Educational Studies in Mathematics, 92, 91-105. https://doi.org/10.1007/s10649-015-9667-2

Haider, H., Gaschler, R., Vaterrodt, B., \& Frensch, P. A. (2014). How we use what we learn in Math: An integrative account of the development of commutativity. Frontline Learning Research, 2, 1-21. https://files.eric.ed.gov/fulltext/EJ1090841.pdf

Harnishfeger, K. K., \& Pope, R. S. (1996). Intending to forget: The development of cognitive inhibition in directed forgetting. Journal of Experimental Child Psychology, 62, 292-315. https://doi.org/10.1006/jecp.1996.0032

Hasher, L., Lustig, C., \& Zacks, R. (2007). Inhibitory Mechanisms and the Control of Attention. In A. Conway, C. Jarrold, A. Kane, A. Miyake, \& J. Towse (Eds.), Variation in working memory (pp. 
227-249). Oxford University Press.

https://doi.org/10.1093/acprof:oso/9780195168648.003.0009

Hewitt, D. (1999). Arbitrary and necessary part 1: A way of viewing the mathematics curriculum. For the Learning of Mathematics, 19, 2-9. http://www.jstor.org/stable/10.2307/40248303

Hiebert, J., Carpenter, T. P., Fennema, E., Fuson, K., Human, P., Murray, H., Olivier, A., \& Wearne, D. (1996). Problem solving as a basis for reform in curriculum and instruction: The case of mathematics. Educational Researcher, 25, 12-21.

https://doi.org/10.3102/0013189X025004012

Jonsson, B., Kulaksiz, Y. C., \& Lithner, J. (2016). Creative and algorithmic mathematical reasoning: effects of transfer-appropriate processing and effortful struggle. International Journal of Mathematical Education in Science and Technology, 47, 1206-1225.

https://doi.org/10.1080/0020739X.2016.1192232

Karmiloff-Smith, A. (1992). Beyond modularity: A developmental perspective on cognitive science. Behavioral and Brain Sciences, 17, 693-745. https://doi.org/10.3109/13682829409041485

Kieran, C. (1981). Concepts associated with the equality symbol. Educational Studies in Mathematics, 12, 317-326. https://doi.org/10.1007/BF00311062

Kim, M. S., \& Cave, K. R. (1995). Spatial attention in visual search for features and feature conjunctions. Psychological Science, 6, 376-380. https://doi.org/10.1111/j.14679280.1995.tb00529.x

Klein, J. S., \& Bisanz, J. (2000). Preschoolers doing arithmetic: the concepts are willing but the working memory is weak. Canadian Journal of Experimental Psychology, 54, 105-116. https://doi.org/10.1037/h0087333

Knuth, E. J., Alibali, M. W., McNeil, N. M., Weinberg, A., \& Stephens, A. C. (2005). Middle school students' understanding of core algebraic concepts: Equivalence \& Variable. Zentralblatt Für 
Knuth, E. J., Stephens, A. C., McNeil, N. M., \& Alibali, M. W. (2006). Does understanding the equal sign matter? Evidence from solving equations. Journal for Research in Mathematics Education, $37,297-312$.

Larsen, S. (2010). Struggling to disentangle the associativie and commutative properties. For the Learning of Mathematics, 30(1), 37-42.

Laski, E. V., Casey, B. M., Yu, Q., Dulaney, A., Heyman, M., \& Dearing, E. (2013). Spatial skills as a predictor of first grade girls' use of higher level arithmetic strategies. Learning and Individual Differences, 23, 123-130. https://doi.org/10.1016/j.lindif.2012.08.001

Lemaire, P., \& Siegler, R. S. (1995). Four aspects of strategic change: Contributions to children's learning of multiplication. Journal of Experimental Psychology, 124, 83-97. https://doi.org/10.1037/0096-3445.124.1.83

Luchins, A. S. (1942). Mechanization in problem solving: The effect of Einstellung. Psychological Monographs, 54, 1-95. http://doi.apa.org/getdoi.cfm?doi=10.1037/h0093502

Macleod, C. M. (2007). The concept of inhibition in cognition. In D. Macleod \& C. Gorfein (Eds.), Inhibition in cognition (pp. 3-23). American Psychological Association. https://doi.org/10.1037/11587-000

McMullen, J., Brezovszky, B., Rodríguez-Aflecht, G., Pongsakdi, N., Hannula-Sormunen, M. M., \& Lehtinen, E. (2016). Adaptive number knowledge: Exploring the foundations of adaptivity with whole-number arithmetic. Learning and Individual Differences, 47, 172-181. https://doi.org/10.1016/j.lindif.2016.02.007

McNeil, N. M., \& Alibali, M. W. (2005). Why won't you change your mind? Knowledge of operational patterns hinders learning and performance on equations. Child Development, 76, 883-899. https://doi.org/10.1111/j.1467-8624.2005.00884.x 
McNeil, N. M., Chesney, D. L., Matthews, P. G., Fyfe, E. R., Petersen, L. A., Dunwiddie, A. E., \& Wheeler, M. C. (2012). It pays to be organized: Organizing arithmetic practice around equivalent values facilitates understanding of math equivalence. Journal of Educational Psychology, 104, 1109-1121. https://doi.org/10.1037/a0028997

McNeil, N. M., Fyfe, E. R., Petersen, L. A., Dunwiddie, A. E., \& Brletic-Shipley, H. (2011). Benefits of practicing 4=2+2: Nontraditional problem formats facilitate children's understanding of mathematical equivalence. Child Development, 82, 1620-1633. https://doi.org/10.1111/j.14678624.2011.01622.x

McNeil, N. M., Grandau, L., Knuth, E. J., Alibali, M. W., Stephens, A. C., Hattikudur, S., \& Krill, D. E. (2006). Middle-school students' understanding of the equal sign: The books they read can't help. Cognition and Instruction, 24, 367-385. https://doi.org/10.1207/s1532690xci2403_3

National Council Of Teachers Of Mathematics. (2000). Principles and Standards for School Mathematics. School Science and Mathematics, 47, 868-279. https://doi.org/10.1111/j.19498594.2001.tb17957.x

National Mathematics Advisory Panel. (2008). Foundations for success: The final report of the National Mathematics Advisory Panel (Vol. 37, Issue 9). https://doi.org/10.3102/0013189X08329195

Nigg, J. T. (2000). On inhibition/disinhibition in developmental psychopathology: Views from cognitive and personality psychology and a working inhibition taxonomy. Psychological Bulletin, 126, 220-246. https://doi.org/10.1037/0033-2909.126.2.220

Patel, P., \& Canobi, K. H. (2010). The role of number words in preschoolers' addition concepts and problem-solving procedures. Educational Psychology, 30, 107-124. https://doi.org/10.1080/01443410903473597

Peng, P., Namkung, J., Barnes, M., \& Sun, C. (2016). A Meta-Analysis of Mathematics and Working 
Memory: Moderating Effects of Working Memory Domain, Type of Mathematics Skill, and Sample Characteristics. Journal of Educational Psychology, 108(4), 455-473.

https://doi.org/10.1037/edu0000079

Peters, G., De Smedt, B., Torbeyns, J., Ghesquière, P., \& Verschaffel, L. (2010). Adults' use of subtraction by addition. Acta Psychologica, 135, 323-329.

https://doi.org/10.1016/j.actpsy.2010.08.007

Petersen, S. E., \& Posner, M. I. (2012). The attention system of the human brain: 20 years after. Annual Review of Neuroscience, 35, 73-89. https://doi.org/10.1146/annurev-neuro-062111150525

Pettigrew, C., \& Martin, R. C. (2014). Cognitive declines in healthy aging: Evidence from multiple aspects of interference resolution. Psychology and Aging, 29, 187-204. https://doi.org/10.1037/a0036085

Piaget, J. (1952). The child's conception of number. Routledge \& Kegan Paul.

Piaget, Jean. (1973). To Understand is to Invent: The Future of Education. International Commission on the Development of Education.

Raghubar, K. P., Barnes, M. A., \& Hecht, S. A. (2010). Working memory and mathematics: A review of developmental, individual difference, and cognitive approaches. Learning and Individual Differences, 20, 110-122. https://doi.org/10.1016/j.lindif.2009.10.005

Rasmussen, C., Ho, E., \& Bisanz, J. (2003). Use of the mathematical principle of inversion in young children. Journal of Experimental Child Psychology, 85, 89-102. https://doi.org/10.1016/S00220965(03)00031-6

Rittle-Johnson, B., \& Schneider, M. (2014). Developing conceptual and procedural knowledge of mathematics. In Oxford Handbook of Numerical Cognition (pp. 1118-1134). https://doi.org/10.1093/oxfordhb/9780199642342.013.014 
Rittle-Johnson, B., Siegler, R. S., \& Alibali, M. W. (2001). Developing conceptual understanding and procedural skill in mathematics: An iterative process. Journal of Educational Psychology, 93, 346-362. https://doi.org/10.1037/0022-0663.93.2.346

Robertson, I. H., Ward, T., Ridgeway, V., \& Nimmo-Smith, I. (1996). The structure of normal human attention: The Test of Everyday Attention. Journal of the International Neuropsychological Society : JINS, 2, 525-534. https://doi.org/10.1017/S1355617700001697

Robinson, K. M. (2001). The validity of verbal reports in children's subtraction. Journal of Educational Psychology, 93, 211-222. https://doi.org/10.1037/0022-0663.93.1.211

Robinson, K. M., \& Beatch, J.-A. (2016). Conceptual knowledge of arithmetic for Chinese- and Canadian-educated adults. Canadian Journal of Experimental Psychology/Revue Canadienne de Psychologie Expérimentale, 70, 335-342.

Robinson, K. M., \& Dubé, A. K. (2009a). Children's understanding of addition and subtraction concepts. Journal of Experimental Child Psychology, 103, 532-545. https://doi.org/10.1016/j.jecp.2008.12.002

Robinson, K. M., \& Dubé, A. K. (2009b). Children's understanding of the inverse relation between multiplication and division. Cognitive Development, 24, 310-321. https://doi.org/10.1016/j.cogdev.2008.11.001

Robinson, K. M., \& Dubé, A. K. (2012). Children's use of arithmetic shortcuts: The role of attitudes in strategy choice. Child Development Research, 2012, 1-10. https://doi.org/10.1155/2012/459385

Robinson, K. M., \& Dubé, A. K. (2013). Children's additive concepts: Promoting understanding and the role of inhibition. Learning and Individual Differences, 23, 101-107. https://doi.org/10.1016/j.lindif.2012.07.016

Robinson, K. M., Dubé, A. K., \& Beatch, J.-A. (2017). Children's understanding of additive concepts. 
Journal of Experimental Psychology, 156, 16-28. https://doi.org/10.1016/j.jecp.2016.11.009

Robinson, K. M., Dubé, A. K., \& Beatch, J. A. (2016). Children's multiplication and division shortcuts: Increasing shortcut use depends on how the shortcuts are evaluated. Learning and Individual Differences, 49, 297-304. https://doi.org/10.1016/j.lindif.2016.06.014

Robinson, K. M., \& LeFevre, J.-A. (2012). The inverse relation between multiplication and division: Concepts, procedures, and a cognitive framework. Educational Studies in Mathematics, 79, 409-428. https://doi.org/10.1007/s10649-011-9330-5

Robinson, K. M., \& Ninowski, J. E. (2003). Adults' understanding of inversion concepts: how does performance on addition and subtraction inversion problems compare to performance on multiplication and division inversion problems? Canadian Journal of Experimental Psychology, $57,321-330$.

Robinson, K. M., Ninowski, J. E., \& Gray, M. L. (2006). Children's understanding of the arithmetic concepts of inversion and associativity. Journal of Experimental Child Psychology, 94, 349-362. https://doi.org/10.1016/j.jecp.2006.03.004

Robinson, K. M., Price, J. A. B., \& Demyen, B. (2018). Understanding arithmetic concepts: Does operation matter? Journal of Experimental Child Psychology, 166, 421-436. https://doi.org/10.1016/j.jecp.2017.09.003

Schneider, M., \& Stern, E. (2010). The developmental relations between conceptual and procedural knowledge: A multimethod approach. Developmental Psychology, 46, 178-192. https://doi.org/10.1037/a0016701

Sherman, J., \& Bisanz, J. (2009). Equivalence in Symbolic and Nonsymbolic Contexts: Benefits of Solving Problems With Manipulatives. Journal of Educational Psychology, 101, 88-100. https://doi.org/10.1037/a0013156

Shrager, J., \& Siegler, R. S. (1998). SCADS: A model of children's strategy choices and strategy 
discoveries. Psychological Science, 9, 405-410. https://doi.org/10.1111/1467-9280.00076

Shumway, R. J. (1974). Negative Instances in Mathematical Concept Acquisition: Transfer Effects between the Concepts of Commutativity and Associativity. Journal for Research in Mathematics Education. https://doi.org/10.2307/748846

Siegler, R. S. (1988). Individual differences in strategy choices: good students, not-so-good students, and perfectionists. Child Development, 59, 833-851. https://doi.org/10.1111/j.1467-

8624.1988.tb03238.x

Siegler, Robert S., \& Araya, R. (2005). A computational model of conscious and unconscious strategy discovery. Advances in Child Development and Behavior, 33, 1-42.

https://doi.org/10.1016/S0065-2407(05)80003-5

Siegler, Robert S, \& Stern, E. (1998). Conscious and unconscious strategy discoveries:A microgenetic analysis. Journal of Experimental Psychology: General, 127, 377-397.

https://doi.org/10.1037/0096-3445.127.4.377

Stahl, C., Voss, A., Schmitz, F., Nuszbaum, M., Tüscher, O., Lieb, K., \& Klauer, K. C. (2014). Behavioral components of impulsivity. Journal of Experimental Psychology: General, 143, 850-886. https://doi.org/10.1037/a0033981

Star, J. R. (2005). Reconceptualizing procedural knowledge. Journal for Research in Mathematics Education, 36, 404-411. http://www.jstor.org/stable/30034943

Torbeyns, J., De Smedt, B., Ghesquière, P., \& Verschaffel, L. (2009). Acquisition and use of shortcut strategies by traditionally schooled children. Educational Studies in Mathematics, 11, 1-17. https://doi.org/10.1007/s10649-008-9155-z

Verschaffel, L., Luwel, K., Torbeyns, J., \& Van Dooren, W. (2009). Conceptualizing, investigating, and enhancing adaptive expertise in elementary mathematics education. European Journal of Psychology of Education, 24, 335-359. https://doi.org/10.1007/BF03174765 
Warren, E. (2003). The role of arithmetic structure in the transition from arithmetic to algebra.

Mathematics Education Research Journal, 15, 122-137. https://doi.org/10.1007/BF03217374

Watchorn, R. P. D., Bisanz, J., Fast, L., LeFevre, J.-A., Skwarchuk, S.-L., \& Smith-Chant, B. L. (2014). Development of mathematical knowledge in young children: attentional skill and the use of inversion. Journal of Cognition and Development, 15, 161-180.

https://doi.org/10.1080/15248372.2012.742899

Yeniad, N., Malda, M., Mesman, J., Van ljzendoorn, M. H., \& Pieper, S. (2013). Shifting ability predicts math and reading performance in children: A meta-analytical study. Learning and Individual Differences, 23, 1-9. https://doi.org/10.1016/j.lindif.2012.10.004

Zazkis, R., \& Rouleau, A. (2017). Order of operations: On convention and met-before acronyms. Educational Studies in Mathematics, 97, 143-162. https://doi.org/10.1007/s10649-017-9789-9

Zentall, T. R. (2005). Selective and divided attention in animals. Behavioural Processes, 69, 1-15. https://doi.org/10.1016/j.beproc.2005.01.004

\section{Captions}

Figure 1: Skills that might be required to identify and execute the associativity shortcut on conducive ' $a+b-c$ ' problems. Thicker lines are hypothesised to play a greater role in each process. Solid lines indicate a hypothesised positive relationship, dashed lines indicate a hypothesised negative relationship. 